\title{
Review of Writing on the Move: Migrant Women and the Value of Literacy
}

Janet Isserlis, Adult Literacy Practitioner, Providence, Rhode Island

In Writing on the Move: Migrant Women and the Value of Literacy, Rebecca Lorimer Leonard articulates ways in which migrant women's uses of literacies and language move and shift through immigration and resettlement, and how ideological, economic, and cultural forces value, devalue or otherwise shape their use of language and literacy. The book's first chapter explores why writing matters; chapters two through four focus on fluidity, fixity and friction, with the fifth chapter analyzing the deep contradictions in the value(s) of literacy that the writer has gleaned from her research.

Leonard engages 25

multilingual writers from 17 countries in a qualitative study and explores how multilingual women encounter and navigate other people's complicated expectations of their abilities and knowledge within English-speaking contexts. The women of varied ages, occupations, and nationalities, whose lives inform the study, share commonalities and differences in their paths and journeys from their home countries to the United States, where the study is based. Through guided and open-ended interviews and conversations, Leonard learns how her participants' expectations are both met and left unfulfilled as they navigate academic, work and community settings. Participants discuss the range of strategies they have developed within work and academic settings in order to utilize language and literacy to meet the needs and purposes of the contexts in which they find themselves. They describe family expectations and challenges, and articulate how they draw on their own sets of language and literacy use in addition to their concomitant abilities to read and understand culture and cultures.

Leonard articulates ways in which heritage languages, colonialism, and other external forces compel women to use one language or another, to navigate different registers in response to 
interlocutors, power, and context. She learns that literacy itself is mobile - a notion that may ask readers to re-conceptualize our own beliefs about the power - or lack of power - that literacy (and its deployment) may carry for multilingual, nonEnglish dominant writers. She explores tensions, names contradictions, and lays out ways in which educators, employers, scholars, and writers can consider the strengths that multilingual writers bring to their studies, work, and communities. In one context, a writer may do well as a multilingual resource (providing ad hoc interpreting services, for example), while in another context she may be challenged by a hospital administration that requires nurses to speak in unaccented English while doctors' abilities or credentials are rarely - if ever - questioned because of their own ways of speaking accented English. Leonard (2017) "found that literate lives are not simply mobile or immobile, free or fixed, successful or failed, but are instead lived at a nexus of prestige, prejudice, and power that creates multiple mobilities, simultaneous struggle and success" (p. 5).

While much of the book's content is illuminating, I did have two other reactions while reading. First, Leonard's focus on literacy's multiple mobilities of fluidity, fixity and friction is complex, overlapping and was - at times - challenging for me to follow. The text requires close attention and rewards its readers with a layered analysis of thick description gleaned from hours of conversations, reflection, and feedback with the author's informants. In addition, my expectations of this book as a literacy practitioner whose primary work has been with basic level English language and literacy learners, were that Leonard would explore ways in which migrant women made their way through Englishspeaking contexts, using the literacy and language strategies available to them. Instead, Leonard presents complicated and layered accounts of the intricacies of women's lives - many of whom are more "advanced" in their use of English language and literacy than the basic level learners with whom I generally work. I had not expected to read about women whose academic accomplishments surpass those of the students I work with (please note I don't privilege those "higher" levels of language and literacy; I do notice that the women profiled in this text have studied in more academically-focused settings, where students I generally work with have focused more closely on communicative skills for work, family, community, and daily life).

While the primary audience for this book might be scholars and those engaged in academic research, the author presents important insights for adult educators across the board as we prepare learners for advanced study, and even if we do not. In her concluding chapter she points to ways in which systemic patterns of valuing particular sorts of literacy and language use can both support and harm immigrant speakers in that these patterns reify and reinforce common expectations of how non-English speakers perform and interact with interlocutors who appear to judge these speakers' abilities based on assumptions about non-English speakers. Accented English? Female speaker? Hmm. I found myself recognizing - and not being proud of - my own assumptions about immigrant women with whom I am in daily contact in a healthcare setting. As educators we pay lip service to valuing everyone's strengths (they know things, they just may not know them in English); this book shakes us by the shoulders and says there's more to know and understand. The strength of this book lies in helping us to understand the intricacies of language and literacy on the move, in stasis and in conflict. The book carries implications for policy in workplaces, the academy and within our advocacy for and amplification of voices of learners and colleagues for whom English is not a first language. 